\title{
Avaliação do ensino híbrido pelos professores no ensino superior nos cursos de licenciatura
}

A educação a distância tem crescido no ensino superior, para conhecer de que forma acontece o ensino híbrido é necessário compreender as dificuldades, os avanços e os desafios apresentados pelos seus envolvidos. Este artigo tem como objetivo compreender os critérios utilizados pelos professores de disciplinas presenciais e online e nas avaliações acadêmicas durante o processo educativo semestral. Pode-se observar que os professores usam critérios diferenciados para avaliar seus alunos nas diferentes modalidades, porém é perceptível que o ensino híbrido tem sido mais eficiente que o ensino totalmente a distância. $O$ processo educativo deve partir de ambas as partes uma vez que a relação entre o professor e aluno, por meio do ensino EAD, muitas vezes só acontece por meio do computador já que o professor atua como mediador do conhecimento.

Palavras-chave: Ensino Híbrido; Avaliação; Ensino a Distância; Educação; Professores.

\section{Evaluation of hybrid teaching by teachers in higher education in undergraduate courses}

Distance education has grown in higher education, in order to know how hybrid learning happens, it is necessary to understand the difficulties, the advances and the challenges presented by its participants. This article aims to understand the criteria used by teachers of online and online subjects and in the academic evaluations during the semester educational process. It can be observed that teachers use differentiated criteria to evaluate their students in the different modalities, however it is noticeable that hybrid teaching has been more efficient than fully distance teaching. The educational process must start from both sides since the relationship between the teacher and the student, through EAD, often happens only through the computer since the teacher acts as mediator of knowledge.

Keywords: Hybrid Teaching; Evaluation; Distance Learning; Education; Teachers.

Débora Lira da Silva (iD)

Faculdade Guaraí, Brasil

http://lattes.cnpq.br/737003302040487

http://orcid.org/0000-0002-8219-611X

deboralira474@gmail.com

Dayane Rodrigues dos Santos (iD)

Faculdade Guaraí, Brasil

http://lattes.cnpq.br/7610035111093252

http://orcid.org/0000-0002-3382-3965

dayane-ro2015@hotmail.com

Daniela Silva Souza (iD)

Faculdade Guaraí, Brasil

http://orcid.org/0000-0002-5299-3476

danielasousa796@gmail.com
Adriana Martins de Sousa (iD)

Faculdade Guaraí, Brasil

https://lattes.cnpq.br/2421856088984908

http://orcid.org/0000-0002-1939-4498

adri-sousa99@hotmail.com

Bruna Alves Nunes (D)

Faculdade Guaraí, Brasil

http://lattes.cnpq.br/4799982613647160

http://orcid.org/0000-0002-5960-332X

brunaalvesnunes4@gmail.com

Ana Paula Barbosa Lima

Faculdade Guaraí, Brasil

http://lattes.cnpq.br/6811986711944591

http://orcid.org/0000-0002-3934-0323

aplima171@gmail.com

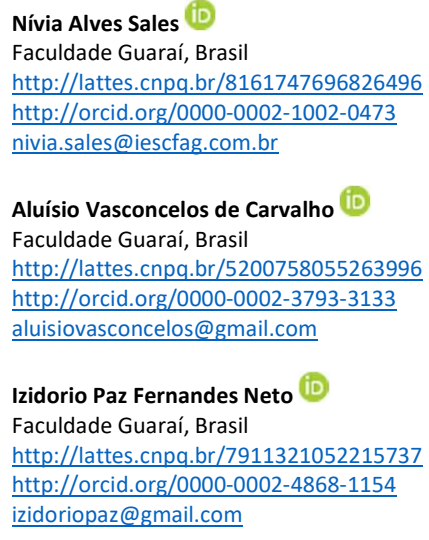

http://lattes cnpq.br/8161747696826496

http://orcid.org/0000-0002-1002-0473

s@iescfag.com.br

Faculdade Guaraí, Brasil

http://lattes.cnpq.br/5200758055263996

http://orcid.org/0000-0002-3793-3133

aluisiovasconcelos@gmail.com

zidorio Paz Fernandes Neto (iD

Faculdade Guaraí, Brasil

http://orcid org/0000-0002-4868-1154

izidoriopaz@gmail.com

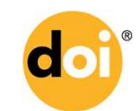

DOI: 10.6008/CBPC2674-6646.2019.001.0001

\section{Referencing this:}

SILVA, D. L.; SANTOS, D. R.; SOUZA, D. S.; SOUSA, A. M.; NUNES, B. A.; LIMA, A. P. B.; SALES, N. A.; CARVALHO, A. V.; FERNANDES NETO, I. P. Avaliação do ensino híbrido pelos professores no ensino superior nos cursos de licenciatura. Civicae, v.1, n.1, p.1-7, 2019. DOI: http://doi.org/10.6008/CBPC2674-6646.2019.001.0001 


\section{INTRODUÇÃO}

O Ensino Híbrido, ou 'blended learning' é um método de ensino inovador utilizado no século XXI que visa proporcionar aos alunos mais facilidade para estudar, promovendo assim uma mistura entre o estudo a distância e o presencial (SILVA et al., 2017).

Este ensino proporciona uma interação aluno e tecnologia, o que na prática já acontece, nesta circunstância voltada para o campo educacional. De acordo com Bacich et al. (2015) existem diferentes propostas de como associar essas atividades, entretanto, na essência, a estratégia consiste em colocar o foco do processo de aprendizagem no aluno e não mais na transferência de informação que o professor realiza no ensino tradicional.

Com o processo focado na aprendizagem do aluno, ele passa a ter um controle sobre o seu próprio conhecimento e o seu tempo, possibilitando a ele produzir o conhecimento a partir da sua própria compreensão, apesar de algumas dificuldades em implementação, ela está cada vez mais presente nas escolas e nas instituições de ensino superior (RODRIGUES JÚNIOR et al., 2016).

A Portaria do Ministério da Educação n.o 2253, de 18 de outubro que instituiu políticas de oferta de disciplinas nas instituições de educação superior, não presenciais, públicas e privadas, definido até $20 \%$ da carga horária completa dos cursos de graduação presenciais, na modalidade de ensino à distância nos cursos de educação superior presencial reconhecido (MATOS et al., 2016).

A junção do modelo a distância com o presencial torna o aluno o principal beneficiado, possuindo ferramentas inovadoras para ajudar no seu aprendizado, as instituições de ensino superior habilitando sua matriz curricular para abranger nos cursos essa inserção do ensino híbrido possibilita múltiplos benefícios tanto para os alunos quanto para elas, o professor possui um novo desafio avaliar nesta nova modalidade de ensino, este modelo deve ser acompanhado de orientações dos professores, uma junção entre professor e aluno (SPINARDI et al., 2018).

Observando as vantagens desta modalidade de ensino, observa-se uma lacuna em relação à aprendizagem do aluno, como a forma que o professor avalia estes alunos, sendo a relação aluno e professor estabelecido em parte ou não através de uma tela seja ela computador, notebook ou celular (SCHIEHL, 2016), afinal é um ensino a distância e o problema pode começar pela dúvida: será que os alunos estão verdadeiramente aprendendo? Como elaborar a avaliação? O que levar em consideração na correção? Os trabalhos e provas foi realmente ele que fez? São perguntas talvez de difíceis respostas, mas que para um professor de disciplina a distância deve ser considerada e discutida para ver ambos os lados deste novo modelo de ensino (FRANCO, 2013).

O modelo atualmente adotado é um grande avanço dentro das escolas e nas universidades, mas este ensino possui seus questionamentos acerca do aprendizado concreto e afirmativo do aluno, como o professor vê se esse aluno está realmente realizando os trabalhos e as provas (NASCIMENTO et al. 2013). De acordo com Cunha (2016), conhecer e compreender os métodos e critérios utilizados pelos educadores ou orientadores é de grande importância, é a partir desse pressuposto que se obtém um melhor aproveitamento 
deste modelo para os alunos e para os professores.

Este artigo tem como objetivo geral analisar o ensino híbrido como instrumento de ensino e os desafios adotados no processo e critérios de avaliação, comparando com o presencial.

\section{METODOLOGIA}

Este estudo tem como finalidade conhecer e compreender os critérios utilizados pelos professores que ministram disciplinas online e comparar com os critérios utilizados pelos professores de disciplinas presenciais das licenciaturas do Instituto Educacional Santa Catarina/Faculdade Guaraí. Portanto, esta pesquisa de campo possuí um caráter quali-quantitativa (RODRIGUES, 2007).

Para implementação desta pesquisa foi elaborado dois formulários online semiestruturados contendo perguntas abertas e fechadas, as questões variavam entre os critérios para a correção das avaliações no ensino a distância e presencial e a opinião de cada professor sobre o ensino híbrido.

Esta pesquisa foi realizada no Instituto Educacional Santa Catarina/Faculdade Guaraí no município de Guaraí (TO), nos cursos de licenciatura de Pedagogia, Educação Física e Ciências Biológicas, utilizando como público-alvo os professores dos referidos cursos, sendo um total de oito professores, quatro docentes que ministram aulas EAD e quatro ministradores de disciplinas presenciais. Para análise dos resultados utilizou-se a estatística descritiva.

\section{RESULTADOS E DISCUSSÃO}

\section{Avaliação online e presencial}

A pesquisa realizada no IESC/Faculdade Guaraí, contou com oito professores, sendo quatro que ministram aulas EAD e quatro com aulas presenciais, com o objetivo de compreender os critérios utilizados para elaboração das avaliações tanto no presencial quanto no online e a opinião de ambos acerca do ensino de disciplinas ead na instituição, bem como sua eficácia, seguindo os critérios adotados por Spinardi et al. (2018).

Ao analisar as respostas abertas obtidas nos formulários dos professores na modalidade presencial (tabela 1), observa-se que a maior parte dos docentes na modalidade presencial utiliza como critério para a elaboração de uma avaliação os conteúdos estudados em sala elencados na ementa da disciplina, portanto o professor ministra um conteúdo que se espera que o aluno aprenda e solicita este possível aprendizado em uma avaliação.

Tabela 1: Critérios para elaboração de avaliações utilizada pelos professores de disciplinas presenciais.

\begin{tabular}{|l|}
\hline Os conhecimentos abordados nas aulas; os conteúdos da ementa; conteúdo mais relevante para a atuação acadêmica. \\
\hline O conteúdo das aulas teóricas e práticas. \\
\hline $\begin{array}{l}\text { Compreensão dos conteúdos aplicados em sala, capacidade de análise e aplicação do conhecimento adquirido, construção de } \\
\text { novos saberes a partir do conteúdo apreendido em sala, campo e cotidiano. }\end{array}$
\end{tabular}

Segundo Pacheco (2002), o critério em uma avaliação, vem para julgar, comparar e apreciar, estes e muitos outros critérios são utilizados pelos professores para julgar e investigar se o aluno aprendeu ou não, 
mas para isso o julgamento deve ser feito de forma justa para que não haja equívocos na hora de avaliar e a investigação deve ser precisa para obter informações concretas dos acadêmicos e isso deve ser feito com muita dedicação pois se trata de um assunto de alta complexidade.

Através da tabela 2, pode se observar que os critérios utilizados para a elaboração de uma avaliação em disciplinas EAD é vasto e por ser uma disciplina online, cada professor possui uma maneira diferente de construir suas avaliações, levando em conta o que considera mais relevante para a aprendizagem do aluno, alguns professores abordam os textos e atividades enviados ao aluno para estudo, bem como as atividades propostas no padrão Enade e as competências necessárias para a formação do aluno.

Tabela 2: Critérios para elaboração de avaliações utilizada pelos professores de disciplinas online.

\begin{tabular}{|l|}
\hline Leitura e resenha de artigo. \\
\hline Padrão Enade. \\
\hline O desenvolvimento de competências necessárias para a formação. \\
\hline Conteúdo trabalhado nos módulos, aulas e material de apoio. \\
\hline
\end{tabular}

Segundo Rothen et al. (2013), o Exame Nacional de Desempenho dos Estudantes é uma prova abrangente, possui como papel a verificação dos conhecimentos dos estudantes sobre os conteúdos programáticos, as competências e habilidades adquiridas pelos alunos. Portanto, proporcionado ao aluno um leque de conhecimentos necessários que lhe serão ofertados para a sua formação.

Os dois modelos de ensino possuem suas particularidades, apesar de possuírem diferenças, os dois levam em consideração os conteúdos abordados em sala, seja ela física ou virtual. Assim, as avaliações são elaboradas de acordo com a visão que o professor possui do que o aluno aprendeu sobre os conteúdos e atividades propostas e realizados, sem ligação com os alunos que irão utilizar estes conteúdos (GATTI, 2003; COSTA, 2007).

Os critérios para elaboração de avaliações sejam elas online ou presencial possui pontos a serem analisados, ao observar na tabela 3 os critérios utilizados para a correção dessas avaliações presenciais, considera-se a capacidade de interpretação que o aluno possui sobre as questões da prova e os conhecimentos adquiridos em sala de aula.

Tabela 3: Critérios de correção de avaliações presenciais.

\begin{tabular}{|l|}
\hline Compromisso e envolvimento com a atividade, bem como o domínio de conteúdo. \\
\hline A resposidade do aluno em compreender, analisar, avaliar, aplicar e interpretar os conhecimentos e conteúdo da avaliação \\
\hline Análise de acertos das questões, capacidade do aluno de interpretar as questões. \\
\hline
\end{tabular}

Nessa perspectiva, o que vale é o esforço e dedicação de professores e alunos para atingir, com maior precisão, os objetivos finais. Anastasiou (2008) ressalta que para construir os critérios, é necessário começar do que foi vivido no processo, isso inclui os objetivos, conteúdos, estratégias vivenciadas e os métodos.

Na tabela 4, obteve-se os critérios de correção de avaliações online, observa-se que os docentes se atentam para a interação dos alunos nas atividades online propostas e na compreensão dos conteúdos estudados, alguns se atentam mais somente aos acertos nas avaliações de múltipla escolha, o que na maior parte das vezes não é condizente com o aprendizado do aluno. Segundo Rodrigues (2015), a avaliação no modelo híbrido precisa ser uma parte constante do processo de aprendizagem do aluno para a sua 
verificação.

Tabela 4: Critérios de correção de avaliações online.

Pontos positivos e negativos do artigo analisado.

Gabarito.

As atividades desenvolvidas e a interação nas atividades online.

Análise do conhecimento e compreensão do conteúdo.

As correções das avaliações online podem gerar um amplo debate, a maioria das atividades são de múltipla-escolha, questões discursivas onde o aluno precisa demonstrar sua capacidade de análise dos conteúdos abordados são minorias, assim os critérios de correção variam de cada professor, uma vez que estes critérios são construídos na individualidade de cada um (GATTI, 2003). Rocha (2006) afirma que as provas objetivas são projetadas para possuir uma única resposta certa e, consequentemente, podendo ser naturalmente automatizados.

\section{Efetividade do Sistema EAD e Presencial}

O ensino híbrido nas instituições de ensino superior está cada vez mais presente, assim nas perguntas fechadas foi possível observar sobre a efetividade do ensino EAD. De acordo com a pesquisa, $75 \%$ dos professores de disciplinas ressaltam a efetividade do ensino a distância enquanto $25 \%$ não concordam com essa modalidade no ensino superior.

O IESC/Faculdade Guaraí trabalha com o ensino EAD, com alguns encontros esporádicos para retirar dúvidas. A maioria dos professores concordam com o ensino online nas instituições de ensino superior, isto pode significar que a introdução deste modelo de ensino traz tanto para os professores quanto para o aluno comodidade por fazer o seu próprio tempo para estudar e realizar as atividades e avaliações propostas, a autonomia do aluno ter que buscar compreender os conteúdos formando sua opinião crítica evidencia o seu auto-disciplinamento na sua própria formação (VILAÇA, 2010; VOIGT, 2007; MORETTO, 2003).

Todos os cursos ofertados pelo IESC/Faculdade Guaraí ofertam pelo menos uma disciplina online por semestre, perguntou-se quanto a obtenção de notas que o aluno tira condiz com o que o professor observa durante as aulas e realização das atividades online, destes, $50 \%$ relataram que sim, enquanto a outra metade não. Consequentemente, para metade dos professores o conhecimento que o aluno demonstra em sala não é condizente com os resultados obtidos nas provas, o que mostra que as avaliações por si só, com caráter apenas somativo e classificatório nem sempre necessariamente é o certo para medir os conhecimentos dos alunos. De acordo com Luckesi (1991) as notas são usadas para amparar uma necessidade de classificar os alunos, onde há uma comparação do desempenho e não dos objetivos que se deseja alcançar.

No sentido de aprovar ou reprovar o aluno, a avaliação como um processo pode deixar de ter esse sentido, logo, passando a fazer parte do processo ensino-aprendizagem (SPINARDI et al., 2018). De acordo com Fiori et al. (2013) pode acontecer os dois casos, muitas vezes a nota não condiz com o que o aluno aprendeu, assim como também pode condizer e as notas só são colocadas devido à pressão dos pais sobre os professores para que eles tenham controle de como seu filho estão se desempenhando na escola.

Para as disciplinas totalmente online $75 \%$ disseram que o aprendizado percebido pelo professor em 
relação ao aluno não condiz com a nota tirada por eles, $25 \%$ concorda que o aluno aprende o que foi ensinado na disciplina. Deve-se observar neste percentual o alto índice de professores que percebe esta situação de notas e aprendizado no modo EAD, abre-se um leque de possibilidades de resposta para essa questão, esta percepção poderá ser por motivo dos alunos não estarem realizando os trabalhos ou as provas visto que são online ou pela realização de trabalhos que demonstram uma compreensão do conteúdo, mas na prova este resultado não é equivalente.

Quando realizada a distância, a avaliação se torna complicada, por não possuir uma interação frente a frente, que possibilita uma avaliação informal do aluno, dando sinal de dedicação, compreensão e interesse, também existe a questão da veracidade do utilizador, ou seja, como garantir que é o aluno que realmente está realizando as avaliações (ROCHA, 2006; GAMA et al., 2006).

\section{CONSIDERAÇÕES FINAIS}

Em virtude dos fatos mencionados podemos perceber a evolução do sistema de ensino, é preciso levar em consideração o avanço na área da tecnologia onde o sistema de ensino não poderia ficar de fora. Contudo, conclui-se que há uma dificuldade encontrada por parte tanto dos alunos quanto dos professores para esse novo meio de educação, pois o costume de ter um professor presente em sala de aula se faz muito necessário em determinado momento. A presença de um professor presencialmente poderia sanar mais dúvidas, aconselhar melhor ou até mesmo orientar de um jeito regular esse aluno.

Portanto, é preciso lembrar que esse desenvolvimento é feito de forma muito lenta e muito ainda precisa ser mudado para que essa interação seja vista como algo que faça a diferença, os alunos precisam está realmente comprometidos com esse recurso, sabendo que muitas vezes, a dedicação deve ser reciproca no processo de ensino-aprendizagem em ambas as partes.

\section{REFERÊNCIAS}

ANASTASIOU, L. G. C.. Avaliação, ensino e aprendizagem: anotações para um começo de conversa. In: CORDEIRO, T. S. C.; MELO, M. M. O.. Formação pedagógica e docência do professor universitário: um debate em construção. Recife: EdUFPE, 2008. p.319-83

BACICH, L.; NETO, A. T.; MELLO TREVISANI, F. M.. Ensino híbrido: personalização e tecnologia na educação. Penso, 2015.

COSTA, F. A.. A aprendizagem como critério de avaliação de conteúdos educativos on-line. Cadernos Sacausef, p.45-54, 2007.

CUNHA, L. C. M. M.. Avaliação escolar: critérios e instrumentos utilizados pelos professores do Ensino Fundamental I. Trabalho de Conclusão de Curso (Licenciatura em Pedagogia a Distância) - Universidade Federal do Rio Grande do Norte, Currais Novos, 2016.

ENSINO Híbrido: Conheça o conceito e entenda a prática; Nova Escola, 2015.
FIORI, G.; BERTOLDO, R. R.. Contextualizando o ensino de química por meio das atividades experimentais. In: Os desafios da escola pública paranaense na perspectiva do professor PDE. Cadernos PDE, v.1, 2013.

FRANCO, M. L. P. B.. Pressupostos epistemológicos da avaliação educacional. Cadernos de pesquisa, n.74, p.63-67, 2013.

GAMA, Z. J.; OLIVEIRA, E. S. G.. A avaliação da aprendizagem: a proposta do curso de Pedagogia a distância do Consórcio CEDERJ. Avaliação da aprendizagem em educação online. São Paulo: Edições Loyola, 2006.

GATTI, B. A.. O professor e a avaliação em sala de aula. Estudos em avaliação educacional, n.27, p.97-114, 2003.

RODRIGUES JÚNIOR, E.; CAMARGO, N. M.. Uma experiência em ação: aprofundando conceito e inovando a prática pedagógica através do ensino híbrido. In: SIMPÓSIO INTERNACIONAL DE EDUCAÇÃO A DISTÂNCIA E ENCONTRO DE PESQUISADORES EM EDUCAÇÃO A DISTÂNCIA. Anais. 2016. 
LUCKESI, C. C.. Avaliação da aprendizagem escolar: apontamentos sobre a pedagogia do exame. Tecnologia educacional, v. 20, n. 101, 1991.

MATOS, H. A.; NETO, D. S.. Educação a distância ou virtualidade na educação presencial brasileira?. SIED: EnPED-Simpósio Internacional de Educação a Distância e Encontro de Pesquisadores em Educação a Distância, 2016.

MORETTO, V. P.. Prova: um momento privilegiado de estudo - não um acerto de contas. Rio de Janeiro: DP\&A, 2003.

NASCIMENTO, L. F.; CZYKIEL, R.; FIGUEIRÓ, P. S.. Presencial ou a distância: a modalidade de ensino influencia na aprendizagem?. Administração: Ensino e Pesquisa, v. 14, n. 2, p. 311-341, 2013.

PACHECO, J. A.. Critérios de avaliação na escola. In: Avaliação das aprendizagens: das concepções às práticas. Lisboa: Departamento da Educação Básica, p. 53 - 64, 2002.

ROCHA, H. V.; OTSUKA, J. L.; FREITAS, C. E.; FERREIRA, T. B.. Avaliação Online: O modelo de suporte tecnológico do Projeto TelEduc. Avaliação da aprendizagem em educação online, p. 347, 2006.

RODRIGUES, L. A.. Uma nova proposta para o conceito de Blended Learning. Interfaces da Educação, v. 1, n. 3, p. 5-22, 2015.
RODRIGUES, W. C.. Metodologia científica. Paracambi: Faetec/IST, v. 40, 2007.

ROTHEN, J. C.; BARREYRO, G. B.. Expansão da educação superior no Brasil e avaliação institucional: um estudo do Sistema Nacional de Avaliação da Educação Superior (SINAES) na "Revista Avaliação". Série-Estudos-Periódico do Programa de Pós-Graduação em Educação da UCDB, n. 30, 2013.

SCHIEHL, E. P.; GASPARINI, I.. Contribuições do Google Sala de Aula para o Ensino Híbrido. RENOTE, v. 14, n. 2, 2016.

SILVA, M. R. C.; MACIEL, C.; ALONSO, K. M.. Hibridização do ensino nos cursos de graduação presenciais das universidades federais: uma análise da regulamentação. Revista Brasileira de Política e Administração da Educação, v.33, n.1, p.95-117, 2017.

SPINARDI, J. D.; BOTH, I. J.. Blended learning: o ensino híbrido e a avaliação da aprendizagem no ensino superior. Boletim Técnico do Senac, v.44, n.1, 2018.

VILAÇA, M. L. C.. Educação a Distância e Tecnologias: conceitos, termos e um pouco de história. Revista Magistro, v.2, n.2, 2010.

VOIGT, E.. A ponte sobre o abismo: educação semipresencial como desafio dos novos tempos. Estudos Teológicos, v.47, n.2, p.44-56, 2007.

A CBPC - Companhia Brasileira de Produção Científica (CNPJ: 11.221.422/0001-03) detém os direitos materiais desta publicação. Os direitos referem-se à publicação do trabalho em qualquer parte do mundo, incluindo os direitos às renovações, expansões e disseminações da contribuição, bem como outros direitos subsidiários. Todos os trabalhos publicados eletronicamente poderão posteriormente ser publicados em coletâneas impressas sob coordenação da Cognitionis Publishing, da Companhia Brasileira de Produção Científica e seus parceiros autorizados. Os (as) autores (as) preservam os direitos autorais, mas não têm permissão para a publicação da contribuição em outro meio, impresso ou digital, em português ou em tradução. 